DOI 10.37882/2223-2982.2021.02.33

\title{
О МОДЕЛИ ФОРМИРОВАНИЯ АНТИКОРРУПЦИОННОГО МИРОВОЗРЕНИЯ У КУРСАНТОВ, ОБУЧАЮЩИХСЯ В ВУЗАХ МВД РЕСПУБЛИКИ КАЗАХСТАН
}

\section{ABOUT THE MODEL OF FORMATION OF ANTI-CORRUPTION WORLDVIEW OF STUDENTS ENROLLED IN UNIVERSITIES OF THE MINISTRY OF INTERIOR OF THE REPUBLIC OF KAZAKHSTAN \\ E. Fedotova}

Summary: The article is devoted to the consideration of the question that the educational environment of higher educational institutions of the Ministry of Internal Affairs is the strongest factor in the formation of the personality of a police officer. The author emphasizes that a properly designed educational process, including the educational, extracurricular and service activities of cadets, is the main condition for the formation of a stable anti-corruption worldview of a cadet. Described in the article, the study was able to reasonably describe the psychological profile of individuals prone to commit corruption offences, on the basis of which was allocated to criteria and indicators of formation of anticorruption Outlook: motivational value, cognitive, emotional, and effective. The author briefly describes the course of experimental work, a special model developed and implemented in the educational process, one of the links of which was the Program for the formation of an anti-corruption worldview.

The author describes the brief results of the primary diagnosis and provides the results of the final diagnosis after the implementation of the Program. The article presents some numerical indicators of differences according to the criteria established at the beginning of the study between the two samples: differences in the value, motivational, emotional-volitional and activity-practical spheres. The results of the study showed the effectiveness of the model used in the framework of the anti-corruption worldview formation.

Keywords: anti-corruption worldview, criteria and indicators of anticorruption worldview, individual qualities of cadets, educational program, educational process of departmental universities.

\author{
Федотова Елена Сергеевна \\ Костанайская академия МВД РК имени Шракбека \\ Кабылбаева, подполковник полиции, \\ Республика Казахстан, г. Костанай \\ alena8307@mail.ru
}

Аннотация: Статья посвящена рассмотрению вопроса о том, что образовательная среда высших учебных заведений МВД является сильнейшим фактором в становлении личности офицера полиции. Автор делает акцент на том, что правильно спроектированный образовательный процесс, включающий учебную, внеучебную и служебную деятельность курсантов, является главным условием формирования устойчивого антикоррупционного мировоззрения курсанта. Описываемое в статье исследование позволило обоснованно описать психологический портрет личности, склонной к совершению коррупционных правонарушений, на основании которого были выделены критерии и показатели сформированности антикоррупционного мировоззрения: мотивационно-ценностный, когнитивный, эмоционально-волевой и действенно-практический. Автор кратко описывает ход опытно-экспериментальной работы, разработанную и внедрённую в образовательный процесс специальную модель, одним из звеньев которой была Программа формирования антикоррупционного мировоззрения.

Автор описывает краткие итоги первичной диагностики и приводит результаты итоговой диагностики после реализации Программы. В статье приведены некоторые цифровые показатели различий по установленным в начале исследования критериям между двумя выборками: различия в ценностной, мотивационной, эмоционально-волевой и деятельностно-практической сферах. Результаты исследования показали эффективность примененной в рамках него модели формирования антикоррупционного мировоззрения.

Ключевые слова: антикоррупционное мировоззрения, критерии и показатели антикоррупционного мировоззрения, индивидуальные качества личности курсантов, воспитательная программа, образовательный процесс ведомственных вузов. бучение курсантов в ведомственных вузах одной из главных целей ставит подготовку таких специалистов, которые будут соответствовать требованиям, позволяющим им качественно и эффективно выполнять профессиональные обязанности. В Республике Казахстан, помимо других нормативных актов, конкретные требования к личности сотрудника полиции излагает «Стандарт полицейского», принятый приказом Министра внутренних дел Республики Казахстан от 24 апреля 2020 года. В этом нормативном документе в числе про- чих значатся такие качества, которые объединяются понятием «антикоррупционное мировоззрение».

В рамках своего научного исследования в течение нескольких лет мы занимались вопросом формирования антикоррупционного мировоззрения у курсантов, применяя при этом специально разработанную педагогическую модель. Эта модель включала в себя несколько компонентов: методологический, организационно-методический, содержательный и оценочный. Реализовы- 
валась она в несколько этапов: проектировочный, организационный, преобразовательный и оценочный. Проектировочный этап включал изучение наиболее эффективных методологических подходов, подбор инструментария для проведения диагностики сформированности антикоррупционного мировоззрения; организационный этап включал определение принципов и условий, способствующих формированию антикоррупционного мировоззрения у курсантов; преобразовательный этап проходил с применением специально разработанной программы, включающей мероприятия учебной, внеучебной и служебной деятельности; оценочный же этап проходил в форме диагностики результатов проведенных мероприятий и анализа их эффективности.

Оценка результатов экспериментальной работы проводилась в соответствии с выдвинутыми критериями и показателями: мотивационно-ценностным, когнитивным, эмоционально-волевым, действенно-практическим (поведенческим) [2, с. 6].

Основное целевое действие по формированию антикоррупционного мировоззрения пришлось на реализацию программы, которая включала в себя мероприятия обучающего, воспитательного, патриотического характера, как то: изучение дисциплин антикоррупционной тематики, организация клуба «Молодежная антикоррупционная инициатива» при поддержке Управления акимата Костанайской области по вопросам молодежной политики, который имел колоссальный эффект в формирующем эксперименте, организация и проведение круглых столов, семинаров, игр КВН, флешмобов, баттлов и других молодежных мероприятий, основной мыслью которых было формирование антикоррупционных идей у будущих полицейских.

Основной особенностью модели формирования антикоррупционного мировоззрения была идея использования индивидуального подхода в работе, опора на личностные качества каждого курсанта, поиск потенциала личности, который можно было бы использовать в формирующей работе.

При подборе инструментария оценки уровня сформированности антикоррупционного мировоззрения курсантов, обучающихся в вузах МВД РК, мы опирались на известные, валидные методы психолого-педагогической диагностики: Опросник УСК (уровень субъективного контроля) Джулиана Роттера, тест «Иерархия потребностей» модификация И.А. Акиндиновой, методика диагностики нравственной воспитанности М.И. Шиловой, методика многофакторного исследования личности Кеттела (фактор G и фактор Q3), тест «Ценностные ориентации» (М. Рокич), методику «Диагностика уровня эмпатии» И.М. Юсупова и дополнительные авторские опросники - тест «Что Вы знаете о коррупции?» и анкету для кураторов «Антикоррупционная деятельность курсантов» [1].

Общая оценка сформированности антикоррупционного мировоззрения подразумевала несколько уровней:

- эмочионально-чувственный - низкий, - которому соответствует чувственное познание мира, где антикоррупционно-мировоззренческие знания нецелостны, фрагментарны; антикоррупционные ценности недостаточно сформированы; убеждения, идеалы, связанные с антикоррупционным поведением, выражены слабо; направленность и установки в антикоррупционной сфере не определены;

- когнитивно-рефлексивный - средний - антикоррупционно-мировоззренческие знания в целом личностью усвоены; ценности, идеалы, принципы и убеждения сформированы; антикоррупционная направленность и установки частично сформированы и соответствуют требованиям;

- деятельностно-практический - высокий - антикоррупциоонные знания полные и имеют практическое применение; антикоррупционные ценности устойчивы; убеждения, идеалы, принципы сформированы на высоком уровне, лежат в основе правоохранительной деятельности; направленность и установки в антикоррупционной сфере устойчивы и применяются на практике; поведение имеет рационально-логический характер.

Внедрение предлагаемой модели формирования антикоррупционного мировоззрения курсантов, обучающихся в вузах МВД предполагает соблюдение следующих условий:

- последовательное насыщение учебных дисциплин и воспитательных мероприятий, направленных на формирование антикоррупционного мировоззрения, соответствующим содержанием;

- ориентирование курсантов в разных видах деятельности на интеграцию личных и профессиональных духовно-нравственных интересов;

- включение курсантов в активную учебную, внеучебную и служебную деятельность, обеспечивающую усвоение, воспроизведение и осознание ответственности за соблюдение антикоррупционных правовых и моральных норм;

- создание педагогически оправданной культурнообразовательной среды в вузе;

- последовательное усложнение ролевого участия курсантов в учебной, внеучебной и служебной деятельности: от когнитивного до рефлексивнопрактического уровня [4].

Для подтверждения эффективности разработанной модели и определения возможности ее применения на 
практике была разработана соответствующая Программа реализации.

Базой исследования стала Костанайская академия МВД Республики Казахстан имени Шракбека Кабылбаева. Всего в исследовании участвовало 389 курсантов с 2016 по 2020 гг.

Приступая к организации педагогического процесса, мы задумались о том, каковы же социальные и личностные характеристики самих курсантов, на которые нацелен педагогический процесс.

Результаты опроса показали, что курсанты - это молодые люди с не вполне ясными представлениями об особенностях предстоящей профессии, но уверенностью в своем будущем (68\%), с высоким уровнем притязаний (82\%), адекватной самооценкой (75\%). Считают себя перспективными для реализации в профессии 91\% опрошенных, открытыми для коммуникации с другими курсантами себя признают 84\%. Коммуникация со сверстниками за пределами учебного заведения затруднена по причине закрытости ведомственного учебного заведения, поэтому об уменьшении или сокращении контактов с «гражданскими» сверстниками заявили 67\%, участвовавших в опросе. Общение в интернет-пространстве для курсантов ведомственных вузов Республики Казахстан также затруднено из-за запрета на использование смартфонов на территории режимного учреждения, которым является ведомственный вуз, поэтому 77\% курсантов признают, что испытывают дефицит информации и общения в виртуальном пространстве. На вопрос о том, что оказывает большее влияние на формирование их личности, курсанты отвечают: семья (42\%), офицеры курсового звена и преподаватели вуза (53\%), друзья (16\%), другие курсанты (27\%), свою значимость в формировании собственной личности признают только 7\% курсантов, что указывает на преобладание у большинства внешнего (экстернального) локуса контроля.

Свою нравственность оценивают как высокую 34\% опрошенных, как среднюю - 61\%. Признают отсутствие возможности открыто выражать свою гражданскую позицию 59\% опрошенных, при этом ссылаясь на нормы, соблюдать которые сотруднику правоохранительных органов предписывает законодательство государства. Надежду на честное продвижение по службе выражают лишь 23\% участников опроса, тогда как $65 \%$ признаются, что уверены в необходимости совершения коррупционных действий для продвижения по службе. Проявляют искренний интерес к будущему государства 61\% опрошенных курсантов, а признают себя патриотами Родины $87 \%$. Готовы к активным и открытым действиям за честность, порядочность и отсутствие коррупции только 13\% опрошенных, что, предположительно, можно объяснить неуверенностью в собственных силах, несформи- рованной мировоззренческой позицией и недостаточным уровнем научных и житейских знаний. Последнее указывает на высокую толерантность к проявлениям коррупции.

Таким образом, анализируя полученные результаты опроса, можно сделать вывод о том, что низкий уровень патриотизма, преобладание у большинства опрошенных внешнего локуса контроля, отсутствие инициативности в решении проблем, неумение открыто и честно выражать свою гражданскую позицию, неверие в справедливость и возможности продвижения по службе благодаря личным успехам - указывают нам на низкий уровень сформированности у курсантов 1 курса, участвующих в исследовании, антикоррупционного мировоззрения.

Анализ содержания образовательного процесса показал, что воспитанию курсантов в Костанайской академии уделяется большое внимание, однако оно привязано к сложившимся традициям и не изобилует гибкостью и индивидуальной ориентированностью на интересы каждой личности. Наиболее устоявшимися направлениями воспитательной работы с курсантами в Костанайской академии являются:

- работа по адаптации курсантов первого курса к условиям обучения и служебной деятельности;

- умственное воспитание курсантов;

- профилактика девиантного поведения у курсантов (наркозависимости, курения, наркомании и игромании);

- воспитание духовности и нравственности курсантов;

- воспитание профессиональных качеств;

- физическое воспитание [3].

Наиболее привлекательными для курсантов являются коллективные формы воспитательной работы, где они в группе могут реализовать свой потенциал. Участники опроса высказывали мнение о том, что воспитательная работа в вузе нуждается в осовременивании: частое проведение тренингов, организацию театрального кружка в стенах вуза, участие в круглых столах и встречах с представителями других вузов в онлайн-формате, расширение поля взаимодействия с гражданским населением, участие в молодежных проектах и т.п. Высказанные идеи легли в основу содержания программы по формированию антикоррупционного мировоззрения.

На этапе констатирующего эксперимента было выяснено, что антикоррупционное мировоззрение большинства курсантов, участвовавших в исследовании сформировано в пределах среднего уровня. Однако нормативно-правовые акты, регламентирующие деятельность сотрудников ОВД, в том числе принятая в 2019 году дорожная карта по модернизации органов внутренних дел Республики Казахстан и «Стандарт по- 
лицейского» призывают действующих сотрудников быть безупречными в профессиональном и личностном плане, а это значит, что необходимо стремиться к повышению уровня сформированности антикоррупционного мировоззрения.

Внедрение Программы в образовательный процесс Костанайской академии МВД Республики Казахстан имени Шракбека Кабылбаева происходило на формирующем этапе эксперимента с 2016 по 2020 год. Экспериментальная группа на протяжении всего периода обучения участвовала в программе антикоррупционного воспитания в учебной, внеучебной и служебной деятельности.

На этапе первичной диагностики были измерены показатели уровня сформированности антикоррупционного мировоззрения, спроектированы выборки испытуемых, отвечающих требованиям релевантности и репрезентативности. Степень различия между выборками была статистически незначимой, что позволило продолжить опытно-экспериментальную работу в экспериментальной группе испытуемых.

В процессе итоговой диагностики уровня сформированности у курсантов антикоррупционного мировоззрения был осуществлен сравнительный анализ данных и изучена динамика исследуемых показателей уровня сформированности исследуемого феномена. Итоговая диагностика проводилась в период завершения курсантами 7 семестра обучения. Статистические значимые различия были обнаружены практически во всех показателях.

Так, при оценке нравственной воспитанности были обнаружены различия в показателях «Патриотизм», «Доброта и отзывчивость», «Самодисциплина».

По результатам анализа результатов методики «Ценностные ориентации» было выявлено, что самыми популярными терминальными ценностями в контрольной группе, так же как и при первичном диагностировании, остались общественное признание, материально обеспеченная жизнь и счастливая семейная жизнь, а инструментальными - независимость, эффективность в делах и смелость. В экспериментальной группе самыми популярными терминальными ценностями стали свобода, любовь и познание, а инструментальными - честность, воспитанность и самоконтроль.

Анализ результатов сравнения базовых потребностей показал приоритет у курсантов контрольной группы потребности в улучшении материального положения, в безопасности и в межличностных связях. В экспериментальной группе приоритет выражается по отношению к потребности в самореализации и уважении со стороны. На основании этого можно судить о высокой степени развитости потребностной сферы личности курсантов.

Когнитивный критерий оценки уровня сформированности у курсантов антикоррупционного мировоззрения также показал статистически значимые различия в уровне знаний курсантов в области антикоррупционного законодательства, а также в степени осознания ими ответственности за совершение коррупционных действий. Уровень знаний в экспериментально группе выше на 20\%, уровень ответственности выше на $24 \%$.

Анализ полученных данных свидетельствует о средних уровнях сформированности знаний и ответственности у курсантов контрольной группы, и высоких - у экспериментальной.

Анализ эмоционально-волевого критерия сформированности антикоррупционного мировоззрения показал, что содержание показателей характеризует курсантов экспериментальной группы, как личностей целенаправленных, с сильной волей, добросовестных и ответственных, склонных к морализированию, с развитым чувством долга и ответственности. Эмоционально-волевой критерий на основании данных показателей можно оценить в целом соответствующим высокому уровню.

Курсанты экспериментальной группы при итоговой оценке продемонстрировали среднегрупповые показатели, соответствующие уровню эмпатии выше среднего. Сознательность поведения (фактор G) у курсантов экспериментальной группы выше на 27\%, а уровень самоконтроля - на $24 \%$.

Результаты опроса кураторов показали, что степень удовлетворенности их проводимой в вузе воспитательной работой значительно возросла по сравнению с первичным опросом. Согласно данным анкетирования около трети курсантов экспериментальной группы принимают активное участие в различных мероприятиях антикоррупционной направленности: круглых столах, встречах с неправительственными организациями, научных конференциях, викторинах и т.д. 33,5\% курсантов изъявляют желание участвовать в волонтерских движениях и лекторских группах на антикоррупционную тематику. Теперь уже зрелыми и самостоятельными кураторы групп называют 74\% курсантов экспериментальной группы, тогда как этот показатель в контрольной группе достиг оценки только в 59\%. Кураторы экспериментальной группы указывают на то, что большая часть курсантов (87\%) свободно и охотно участвуют в дискуссиях на антикоррупционную тематику, а выражают активное негативное отношение к коррупции как явлению $64 \%$. Такой показатель в контрольной группе достиг лишь уровня 44\%. Таким образом, оценить уровень действенно-практического критерия у курсантов эксперимен- 
тальной группы можно как «выше среднего».

Таким образом, анализ результатов формирующего эксперимента на стадии итоговой диагностики показал статистические значимые различия в показателях контрольной и экспериментальной групп и выявил уровень сформированности антикоррупцинного мировоззрения выше среднего у курсантов экспериментальной группы, чем подтвердилась эффективность реализованной нами модели.

Результаты проведенного нами исследования продемонстрировали высокую эффективность созданных нами педагогических условий, и эффективность предлагаемой модели формирования антикоррупционного мировоззрения в целом.

\section{ЛИТЕРАТУРА}

1. Диагностика антикоррупционной позиции курсантов вузов МВД России [Текст]: учебно-методическое пособие / Д.А. Рыбалкин; Казанский юридический ин-т М-ва внутренних дел Российской Федерации. - Казань: КЮИ МВД России, 2017. - 58 с.

2. Радугин А.А. Философия. Курс лекций. 2-е изд., перераб. и доп. - М.: 2004. - 336 с.

3. Старостин Вадим Геннадьевич Ключевые направления воспитания курсантов образовательных организаций МВД России // Ученые записки Казанского юридического института МВД России. 2019. №4 (7)

4. Чушкина А.А. Структура антикоррупционного правосознания: правовая идеология и правовая психология / А. А. Чушкина // Современное право. 2011. - № 3. - С. 23-26.

с Федотова Елена Сергеевна (alena8307@mail.ru).

Журнал «Современная наука: актуальные проблемы теории и практики»

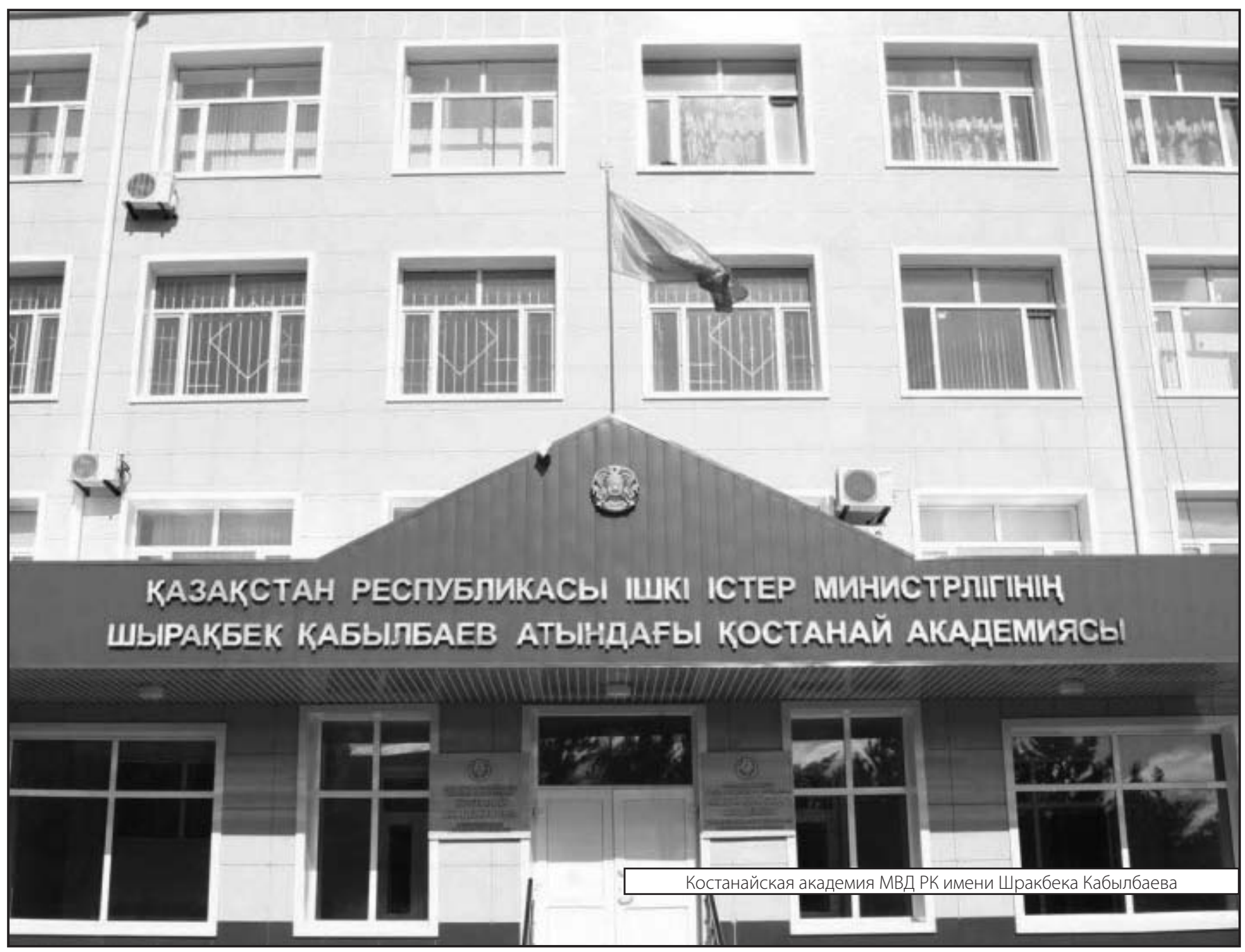

